\title{
Melatonin, Etkileri ve Kullanım Alanları
}

\author{
Ayris Salt' ${ }^{1}$, Metin Çenesiz ${ }^{2}$, Sena Çenesiz ${ }^{1}$ \\ ${ }^{1}$ Ondokuz Mayls Üniversitesi Veteriner Fakültesi Biyokimya Anabilim Dall, Samsun \\ ${ }^{2}$ Ondokuz Mayls Üniversitesi Veteriner Fakültesi Fizyoloji Anabilim Dall, Samsun
}

Geliş Tarihi / Received: 21.02.2017, Kabul Tarihi / Accepted: 21.03.2017

\begin{abstract}
Özet: Melatonin günlük ve mevsimsel değişiklik gösterebilen pineal bezden salgılanan ve suprakiazmatik nukleus tarafından endojen ritmi düzenleyen bir hormondur. Günümüzde tıp ve veteriner hekimlikte ekzojen kullanım alanlarının genişlemesi bu hormonun önemini arttırmıştır. Hücresel kompartmanlara kolayca geçebilen bu hormon güçlü bir antioksidan özellik göstermekle beraber, sirkadyen ritmi düzenleyerek vücutta homeostazisi sağlar. Bağışıklık sistemi üzerine de olumlu etkileri bulunmaktadır. Bazı hayvan türlerinde de üreme siklusunu başlatıcı ya da inhibe edici etki gösterir. Yapılan çalışmalarla melatoninin antikanserojenik etkinliği ortaya koyulmuştur. Bu derlemede melatoninin biyokimyasal özellikleri ile kullanım alanları anlatılmaktadır.
\end{abstract}

Anahtar kelimeler: Antikanserojenik etki, Antioksidan etki, Melatonin

\section{Melatonin, its Effects and Uses}

\begin{abstract}
Melatonin is a hormone which is secreted from the pineal gland and may show a daily-seasonal variations that regulates endogenous rhythm by effecting the suprachiasmatic nucleus. Nowadays, expansion of exogenous usage areas has increased the importance of this hormone in medicine practice. Although this hormone is a powerful antioxidant that can easily pass through cellular compartments. Melatonin regulates the circadian rhythm of the body and maintains homeostasis. There is a beneficial effects on the immune system and has activatory or inhibitory effects on reproductive cycle in some animal species. The studies show that melatonin has also anticarcinogenic activity. In this review we present the biochemical properties of melatonin.
\end{abstract}

Key words: Anticancer activity, Antioxidant activity, Melatonin

\section{Giriș}

Melatonin (5-metoksi-N-asetiltriptamin), 232 moleküler ağırlıklı bir indolamindir. Karanlıkta epifizden salınır. Uyku, reprodüksiyon, sirkadyen ritim ve bağışıklık gibi biyolojik olayların regüle edilmesini sağlar $[15,47]$. Melatonin seviyesi, gün içinde ve farklı mevsimlerde değişiklikler gösterir. Örneğin gün içinde melatonin seviyesi en düşükken gece boyunca yüksek olup kış aylarında da yaz aylarına göre daha süreklidir [33,45].

\section{Biyosentezi ve salgılanmasının regülasyonu}

Dolaşımda bulunan triptofan amino asidi pineal beze gelerek triptofan hidroksilaz ile hidroksillenir. Oluşan 5-OH triptofandan L-aromatik dekarboksilaz ile karboksil grubu ayrılır ve serotonin meydana gelir. Pinealositler içinde serotonin Serotonin-Nasetil transferaz (NAT) tarafindan $\mathrm{N}$-asetil serotonine, ardından da Hidroksiindol-O-metil transferaz
(HIOMT) enziminin yardımıla $\mathrm{N}$-asetil serotonin, melatonine dönüştürülür $[6,23]$. Melatoninin epifizde sentezi, suprakiyazmatik nukleus (SCN)'un 24 saatlik karanlık/aydınlık döngüsüne göre ayarlanır. Sentez ve salınım geceleri yani karanlıkta artar ve 1ş1k ile inhibe olur [24]. Melatoninin epifiz bezi ve koroidal pleksusta depo edildiği düşünülmektedir. Tüm organlara geçebilmektedir ve \%70'i albümine bağlıdır [15]. Postgangliyonik sempatik nöronlar aracılığıla pinealositlere gelen sinirsel impulslar, sirkadyen melatonin ritminin düzenlenmesinde önemli bir role sahiptir. SCN'nin elektriksel aktivitesi geceleri melatonin sentezinin artmasina neden olur [32].

\section{Sentezinin sinirsel uyarımı}

Memelilerde epifiz bezinin, elektriksel impulsları hormonal sekresyonlara dönüştüren nöroendokrin transformatör görevi vardır. Melatonin sentezi ve salınımının 1ş1ktan etkilenmesi sebebi ile gece bo- 
yunca yüksek konsantrasyondadır. Karanlıkta superiyor sempatik gangliyondan $\beta$-adrenerjik postgangliyonik sempatik fibriller aracılığıyla gelen uyarı sentezini arttırırken, aydınlıkta sentez engellenmektedir [15].

\section{Reseptörleri}

$\mathrm{MT}_{1}, \mathrm{MT}_{2}$ ve $\mathrm{MT}_{3}$ olmak üzere 3 reseptör tipi vardır: $\mathrm{MT}_{1}$ ve $\mathrm{MT}_{2}$ G-protein aracılı etki gösterir. $\mathrm{MT}_{1}$ yüksek affiniteli, $\mathrm{MT}_{2}$ ise düşük affinitelidir. Ca-kalmodulin reseptörleri sitoplazmada, retinoid $\mathrm{Z}$ ve $\mathrm{O}$ reseptörleri çekirdektedir. 3 reseptör tipi de moleküler yapılarına ve kromozomal yerleşimlerine göre alt tiplere ayrılırlar. Bu reseptör çeşitliliği sayesinde farklı dokularda farklı işlevler gösterebilen bir nörohormondur [21,38,45].

\section{Melatonin'in patofizyolojisi}

Tamamen karanlıkta, melatonin ritmi belirgin bir şekilde artar [5].Yine de tamamen kör hastalarda sirkadyen ritmle birlikte 1şılkla indüklenen melatonin supresyonu devam eder [9]. Üveitisle ilgili olan retinal değişikliklerde melatonin pikinin düştüğü gözlemlenmiştir [41]. Anormal melatonin seviyeleri başka oküler hastalıklarla ve 1şık algısıyla ilişkili olabilir. Pineal bölgede ki tümöral oluşumlar histolojik tipine göre melatonin salgısını etkiler [6]. Pineal beze infiltre germinoma hücreleri melatonin sekresyonunu azaltırken, parenkimal tümörler düzensiz bir melatonin artışına neden olur. Bu nedenle pineal bez tümörlerinde melatonin seviyesi diyagnostik bir parametre değildir [6].

Çocuklarda görülen, özellikle genetik olan nörolojik hastalıklarda, davranış ve uyku bozukluklarına, anormal melatonin seviyeleri eşlik eder [6]. İskemik felçli hastalarda nokturnal melatonin ritmiyle birlikte hücre aracılı bağışıklıkta bozulma gözlenmiştir [11]. Beyin kökü, 3. ventrikül veya lateral ventrikülde görülen hemorajik lezyonlarda gece yükselmesi yapmadan çok düşük melatonin seviyeleri gözlenmiştir [6]. Düşük melatonin seviyeleri bazı epilepsi formlarında da gözlenmektedir ve insan çalışmaları melatoninin bu hastalarda antikonvülzan etkinlik ve nöbetlerin sıklığında ve EEG izlemelerinde iyileştirme gösterdiğini ortaya koymuştur [6,19]. Depresyondaki hastaların melatonin seviyelerinin düştüğ̈̈; bunun yanı sıra bipolar hastalarının manik ve depresif durumdayken yükselen melatonin seviyesinin duruma göre değişken olduğu gösterilmiştir [6,26]. Antidepresanların, melatonin miktarını arttırdığı bildirilmiştir [47].

\section{Uyku ve sirkadyen ritim üzerine etkileri}

Melatonin, endojen bir düzenleyici olarak homeostazisi sağlar. SCN'den gelen uyarılarla günlük, aylık, y1llık salgılanma farklılıklarıyla tüm hücrelere bilgi verir. $\mathrm{Bu}$ hormon, hücrelerdeki saat genlerini (clock genes) epigenetik olarak kontrol eder $[7,40]$. Ayrıca melatonin, nokturnal sicaklık düşüşünü arttırır ve uykuya dalmayı kolaylaştırır [7].

\section{Kardiyovaskuler sistem üzerine etkileri}

Serebral arterlerde vazokontriksiyon, periferde ise vazodilatasyon etkileri ile birlikte harici alımında kan basıncının düştüğü ve kalp hızının azaldığı rapor edilmiştir $[10,18,27,36]$. Kan basıncındaki bu düşüş postsinaptik $\alpha-1$ adrenerjik resöptör blokajına ve sempatik sistem inhibisyonuna bağlı olabileceği düşünülmüştür [14]. Koroner arter hastalarında gece melatonin salınımın değişmediği fakat melatonin seviyesinin düştüğü bildirilmiştir [2].

\section{Bağışıklık sistemi ve kanser üzerine etkileri}

Pinealektomi yapılan ratlarda timusun yapısının modifiye olduğunu ve farelerde melatonin tedavisinin timüs involüsyonunu engellediği ortaya koyulmuştur [13,30]. Ayrıca melatonin immun sistem hücrelerinin günlük ve mevsimlik düzenlenmesini de sağlar [37]. Ín vivo, yüksek doz melatonin, genel bir immun sistem stimulasyonu sağlar. T hücre aktivasyonunu, lenfosit büyümesini, humoral cevabı arttırır ve yaşla oluşan timüs involüsyonunu inhibe eder [37]. İ vitro çalışmalarda, melatoninin yardımcı T hücresi ve NK hücreleri aktivitesini, IL-2 ve IFN $\gamma$ üretimini, insan monositinde IL-1 mRNA ekspresyonunu arttırdığ gösterilmiştir [37]. Ayrıca viral enfeksiyonların tedavileri sırasında yaşanan çaresizlikler göz önünde bulundurulduğunda melatoninin birçok viral enfeksiyonun tedavisinde destekleyici olarak görev alabileceği bildirilmiştir [22].

Göğüs ve prostat kanser hücrelerinde MT1 melatonin reseptörlerinin sürekli bir şekilde aktif oldu$\breve{g u}$ ve bunun sonucunda da kanser hücrelerinin proliferasyonunu inhibe ettiği ortaya konulmuştur [17]. 
Melatonin, kanser hücresinin büyüme için ihtiyaç duyduğu maddelerden olan linoleik asitin kanser hücresine girmesini sağlayan reseptörleri azaltarak, Ca-kalmodulin kompleksi üzerinden kanser hücresini uyutur ve tümörün büyümesini yavaşlatarak saf antikanserojenik etki gösterir [40].

\section{Melatoninin endokrin ve reprodüktif sistem üzerine etkileri}

Melatoninin antigonadotropik etkileri vardır. Erişkin dişilerde kronik melatonin uygulaması sonucunda ovaryum boyutlarının küçüldüğü ve östrus sıklığında azalma gözlendiği bildirilmiştir [46]. Yüksek doz melatonin gonadotropin seviyelerini düşürürken prolaktin ve growth hormon seviyelerini arttırmaktadır [15]. Melatonin, mevsimsel üreme gösteren hayvanlarda reproduktif aktiviteyi kontrol eder [20]. Kısa günlerde reprodüktif aktivite gösterenlerde koyun, keçi, geyik gibi hayvanlarda gonadları stimüle edici, uzun günlerde reprodüktif aktivite gösterenlerde at, hamster, deve gibi hayvanlarda ise inhibe edici etki yapmaktadır [42].

\section{Kısrakların östrus siklusunda melatoninin görevi}

Kisraklar, mevsimsel poliöstriktir. Östrus siklusu kış ortasından sonra başlar ve sonbahara kadar devam eder. Günışığı süresinin uzaması siklusun başlamasının başlıca nedenidir. Kısraklarda gebeliğin 11 ay sürmesiyle tayların doğumunun ve hayatlarının ilk birkaç ayının, havanın sıcak ve yiyeceğin bol olduğu zamana denk gelmesi sağlanmış olur [8]. Gün 1şı̆̆ farklılıkları melatonin ve progesteron sentezi üzerinden hipotalamus, hipofiz ve ovaryumları kontrol eder [1]. Kışın karanlık saatlerin artmasıyla melatonin sentezi artar. Melatonin, Hipotalamushipofiz-gonadal aksisi'i (HHGA) bloke eder. GnRH salınımı çok düşük amplitüd ve frekansta pulsatil hale gelir. Bu durum FSH, LH ve gonadotropinlerinin salgılanmasinı uyarmaya yetmez [35]. Yazın ve ilkbaharda aydınlık süresinin uzamasıyla melatonin salg1s1 azalır, hipotalamustan GnRH salg1S1 artar. GnRH, hipotalamik-pitüiter portal vasküler sisteme girerek adenohipofize taşınır. Adenohipofizden, FSH ve LH salg1s1 artar. FSH ve LH Hipotalamushipofiz aksisi (HHA) feedback mekanizmaları ile kontrol eder. Her iki gonadotropinde kan ile ovar- yuma taşınarak fonksiyon gösterir. FSH, granülosa hücrelerinde, preovulatör follikülün büyüme-olgunlaşmasını ve östrojen biyosentezini uyarır. LH, teka hücrelerinde oosit olgunlaşması, ovulasyon, korpus luteum oluşması ve gelişimini sağlar. Progesteron sentezini uyarır [35].

\section{Melatoninin kısraklarda reproduktif aktivite regülasyonunda kullanımı}

Melatonin tedavisinin, hipotalamustaki GnRH içeriğini azalttığ1 gösterilmiş olmasına rağmen, $\mathrm{GnRH}$ veya gonadotropinlerin salgilanmasinda akut etkilere sahip olmadığ bildirilmiştir [29,44]. Melatonin tedavisi uygulanan kısraklarda üreme mevsiminin geciktiği gözlenmiştir [28].

\section{Koyunların östrus siklusunda melatoninin görevi}

Koyunlarda gün uzunluğu azaldığında reprodüktif nöroendokrin fonksiyonlar uyarılır, uzadığında baskılanır. Sonbaharda gün uzunluğunun kısalmasıyla birlikte artan melatonin hipotalamus üzerinden GnRH salgısını uyarır [42]. Artan GnRH gonadotropinleri uyararak seksüel siklusu başlatır [5].

\section{Melatoninin koyunlarda reproduktif aktivite regülasyonunda kullanımı}

Östrus senkronizasyonunda, pratikte melatonin hormonu; tek başına veya progestagenler, östrojenler, prostaglandin F2 $\alpha$ (PGF2 $\alpha$ ) ve analoglar1, gebe k1srak serumu gonadotropini (PMSG), gonadotropin salgilaticı hormon (GnRH), human koryonik gonadotropin hormon (HCG)gibi hormonlarla kombine şekilde kullanılmaktadır. Anöstrusta melatonin uygulaması ile reproduktif aktivite uyarılabilir, hipotalamustan GnRH salınımı üstünden LH uyarılması sağlanır [25]. Alan ve ark.'ının yaptığı çalışmada melatonin implant uygulamasının, östrüs ve ovulasyonların normal üreme sezonuna göre 2-2.5 ay erkene alınabileceğini ve yüksek oranda gebelik elde edilebileceğini göstermiştir [42].

\section{Kedilerin östrus siklusunda melatoninin görevi}

Evcil kediler, reprodüktif aktiviteleri aydınlık süresinden etkilenir. Gün uzunluğunun 8 saatten kısa olması dişilerde folikülogenezisi inhibe eder. Gün uzunluğunun 8-14 saat olduğunda 12-26 günde bir siklus tekrar eder [16]. 


\section{Antioksidan etkileri}

Melatonin, direkt ve indirekt mekanizmalarla antioksidan özelliği gösterir. Direkt olarak yüksek oksidan etkili ${ }^{\circ} \mathrm{OH},{ }^{\cdot} \mathrm{H}_{2} \mathrm{O}_{2},{ }^{\circ} \mathrm{O}_{2},{ }^{\circ} \mathrm{HOCl},{ }^{\circ} \mathrm{NO}, \mathrm{ONOO}-$ gibi radikalleri doğrudan temizleyerek biyomolekülleri koruyabildiği bildirilmiştir [4,30]. Melatoninin içindeki pirol halkası ona antioksidan özellik kazandırır; ' $\mathrm{O}_{2}$ varlığında pirol halkası 2, 3-dioksijenaz (IDO) ile enzimatik olarak ya da hemin ile nonenzimatik olarak yıkımıyla yüksek reaktif $\mathrm{N}^{1}$-asetil- $\mathrm{N}^{2}$ formil-5-metoksikinüramin (AFMK) oluşur [13]. $\mathrm{H}_{2} \mathrm{O}_{2}$ varlığında da AFMK oluştuğu ve bu melatonin metabolitinin de radikal tutucu olarak davrandiğ 1 bildirilmiştir [31]. AFMK oluşumunun bir diğer nedeni ise melatoninin $\mathrm{OH}^{*}$ radikaline yüksek affinite ile bağlanıp indolil katyon radikalini oluşturması ardindan bu radikalinde $\mathrm{O}_{2}{ }^{\circ} \mathrm{i}$ yakalayarak $\mathrm{N}^{1}$-asetil$\mathrm{N}^{2}$-formil-5-metoksikinüramin (AFMK)'ye dönüşmesidir. Daha sonra Arilamin formamidazın (AFA) katalizörlüğünde $\quad \mathrm{N}^{1}$-asetil-5-metoksikinüramine (AMK) çevrilmektedir. Ayrıca ${ }^{\circ} \mathrm{HO}$ varlığında indolil radikalinin oluşturduğu 3-hidroksi melatoninin idrarda ki düzeyleri, radikal üretiminin göstergesi$\operatorname{dir}[47]$.

İndirekt olarak SOD, GPx, GR, glukoz-6-fosfat dehidrogenaz (G6PD) ve $\gamma$-glutamilsistein sentetaz gibi antioksidan enzimlerin gen ekspresyonlarını veya aktivitelerini artırarak antioksidan etki gösterir. Melatonin, Nitrik oksit sentetaz (NOS) enziminin pro-enziminin sentezini inhibe eder, lipid peroksidayonunu bask1layarak MDA miktar1n1 azaltır $[6,34,47,12]$. Ayrica bu nörohormonun, DNA, lipidler ve proteinler üzerinde koruyucu etkisi olduğu düşünülmektedir [35]. Melatoninin, zincir reaksiyonlarını kırarak etki gösteren askorbik asit, $\alpha$-tokoferol ve GSH gibi antioksidanlardan fark1 lipid peroksidasyonunun yayılmasını peroksil radikalini yakalayarak durdurmasıdır [47]. Melatonini diğer antioksidanlardan ayıran bir diğer özelliği ise diğer antioksidanlar serbest radikalleri yakaladıktan sonra onlardan daha az toksik olan prooksidanlara dönüşürlerken, melatoninin antioksidan etkisini gösterdikten sonra yine antioksidan etkili ara ürünlere dönüşmesidir. Bu yüzden terminal antioksidan olarak değerlendirilirler [40].

\section{Melatoninin Jetlag'da kullanımı}

Yapılan araştırmalar, transmeridyen yolculukların uyku, günlük ritm ve günlük aktivite üzerine etkisi olduğunu ortaya koymuştur [39]. Uçuş disritmisi bilinen adıyla jetlag, gündüz yorgunluğu, uyanamama hali, gece uykusuzluğu, iştahsızlık, sindirim problemleri, depresif ruh hali, zayıf psikomotor koordinasyon, zayıf idrak gibi semptomlarla kendini gösterir $[39,43]$. Jetlag semptomlarının giderilmesinde özellikle batıdan doğuya olan uçuşlarda; en etkili tedavi melatonin uygulaması olduğu yapılan çalışmalarla ortaya konmuştur [39].

\section{Melatoninin uykusuzluk problemlerinde kullanımı}

Uyku saatinden önce günde bir kere uygulanan (0,5-5mg) melatoninin, uyku kalitesini ve gündüz uyanıklığını arttırdığı gözlenmiştir [39]. Yapılan çalışmalarda, yaşlilarda görülen uyku bozukluklarında melatonin uygulamalarının uykuyu iyileştirdiği bildirilmiştir [48]. Melatoninin kronobiyotik özellikleri fizyolojik uykuyu regüle eder ve uyku fazlarını kaydırarak uyku siklusunu yeniden düzenler [3].

Bütün bu etkilere bakıldığında melatonin hormonunun canlılarda çok önemli fonksiyonları olduğu ve ekzojen kullanımının da çeşitli hastalıklarda, üreme siklusu düzenlemede sağaltım protokolüne girdiği ileri sürülebilir.

\section{Kaynaklar}

1. Alkan S, Horoz H, Kaşıkçı G, Sönmez C, Ak K, (2003). Kısraklarda Üreme Mevsiminin Farklı Dönemlerinde Vaginal Progesteron Uygulamalarının Fertiliteye Etkisi. İstanbul Üniversitesi Veteriner Fak Derg. 29(1), 111-17.

2. Altun A, Yaprak M, Vardar A, Aktoz M, Özbay G, (2001). Decreased nocturnal melatonin secretion in coronary artery disease (abstr). J Coronary Artery Dis. 4: 108.

3. Bendz LM, Scates AC, (2010). Melatonin Treatment for Insomnia in Pediatric patients with Attention-Deficit/ Hyperactivity Disorder. Ann Pharmacother. 44(1), 185-91.

4. Beyer CE, Steketee JD, Saphier D, (1998). Antioxidant properties of melatonin--an emerging mystery. Biochem Pharmacol. 56(10), 1265-1272.

5. Canoğlu E, Sarıbay K, (2012). Koyun ve keçilerde doğum ve jinekoloji. Semacan A, Kaymaz M, Fındık M, Rişvanlı A, Köker A. eds. Çiftlik hayvanlarında doğum ve jinekoloji. Malatya, Medipres Maatbacilık, Malatya. p.521-649.

6. Claustrat B, Brun J, Chazot G, (2005). The basic physiology and pathophysiology of melatonin. Sleep Med Rev. 9: $11-24$.

7. Claustrat B, Geoffriau M, Brun J, Chazot G, (1995). Melatonin in humans: a biochemical marker of the circa- 
dian clock and an endogenous synchronizer. Neurophysiol Clin. 25(6):351-359.

8. Crowell-Davis SL, (2007). Sexual behavior of mares. Horm Behav. 52, 12-17.

9. Czeisler CA, Shanahan TL,Klerman EB, Martens H, Brotman DJ, Emens JS, Klein T, Rizzo JF 3rd (1995). Suppression of melatonin secretion in some blind patients by exposure to bright light. N Engl J Med. 332(1), 6-11.

10. Dubocovich ML, Markowska M, (2005). Functional MT1 and MT2 melatonin receptors in mammals. Endocrine. 27, 101-110.

11. Fiorina P, Lattuada G, Silvestrini C, Ponari O, Dall'Aglio $\mathrm{P}$, (1999) Disruption of nocturnal melatonin rhythm and immunological involvement in ischaemic stroke patients. Scand J Immunol. 50(2), 228-231.

12. Ghosh D, Paul S, Naaz S, Bhowmik D, Dutta M, Ghosh AK, Firdaus SD, Chattopadhyay A, Reiter RJ, Bandyopadhyay $\mathrm{D}$, (2016). Melatonin protects against lead acetate induced oxidative stress-mediated changes in morphology and metabolic status in rat red blood cells: a flow cytometric and biochemical analysis. J Pharm Res.10(6) ,381-402.

13. Hardeland R, Reiter RJ, Poeggeler B, Tan D-X, (1993). The significance of the metabolism of the neurohormone melatonin: Antioxidative protection and formation of bioactive substances. Neurosci Biobehav Rev. 17, 347-357.

14. K-Laflamme A, Wu L, de Champlain J, (1998). Impaired basal sympathetic tone and alpha 1-adrenergic responsiveness in association with the hypotensive effect of melatonin in spontaneously hypertensive rats. Am J Hypertens. 11, 219-29.

15. Koçak A, Çolak A, (1996). Melatonin ve Santral Sinir Sistemi. Turgut Özal Tıp Merkezi Dergisi. 3(3), 237-244.

16. Kutzler MA, (2015). Alternative methods for feline fertility control: Use of melatonin to suppress reproduction. J Feline Med Surg. 17, 753-757

17. Liu J, Clough SJ, Hutchinson AJ, Adamah-Biassi EB, Gorevski MP, and Dubocovich ML, (2016). MT1 and MT2 Melatonin Receptors: A Therapeutic Perspective. Annu. Rev. Pharmacol. Toxicol. 56, 361-383.

18. Lusardi P, Preti P, Savino S, Piazza E, Zoppi E, Fogari R, (1997). Effect of bedtime melatonin ingestion on blood pressure of normotensive subjects. Blood Press Monit. 2, 99- 103.

19. Molina-Carballo A, Muñoz-Hoyos A, Reiter RJ, SánchezForte M, Moreno-Madrid F, Rufo-Campos M, Molina-Font JA, Acuña-Castroviejo D, (1997). Utility of high doses of melatonin as adjunctive anticonvulsant therapy in a child with severe myoclonic epilepsy: two years'experience. J Pineal Res. 23(2), 97-105.

20. Nagy P, Guillaume D, Daels P, (2000). Seasonality in mares. Anim Reprod Sci. 60-61, 245-262.

21. Nosjean O, Ferro M, Coge F, Beauverger P, Henlin JM, Lefoulon F, Fauchere JL, Delagrange P, Canet E, Boutin JA, (2000). Identification of the melatonin-binding site MT3 as the quinone reductase 2. J Biol Chem. 275 (40), 31311-31317.
22. Okur Gümüşova S, Memiş YS, (2014). Bazı Viral Enfeksiyonlarda Melatoninin Etkileri. Atatürk Üniversitesi Vet. Bil. Derg. 9(1), 50-54.

23. Özgüner F, Özcankaya R, Delibaş N, Koyu A, Çalışkan S, (1995). Melatonin ve klinik önemi. SDÜ tıp fakültesi Dergisi. 2(4), 1-6.

24. Öztürk L, Daryerli N, (2000). Melatonin ve Uyku Fizyolojisi. Türkiye Tıp Derg. 7(2), 104-109.

25. Özyurtlu N, Bademkıran S, (2010). Koyunlarda Östrus Senkronizasyonu ve Östrusu Uyarma Yöntemleri. Dicle Üniv Vet Fak Derg. 1(1), 17-22.

26. Pacchierotti C, Iapichino S, Bossini L, Pieraccini F, Castrogiovanni P, (2001). Melatonin in Psychiatric Disorders: A Review on the Melatonin Involvement in Psychiatry. Front Neuroendocrinol. 22(1), 18-32.

27. Paulis L, Simko F, (2007). Blood pressure modulation and cardiovascular protection by melatonin: potential mechanisms behind. Physiol Res. 56, 671-684.

28. Peltier MR, Robinson G, Sharp DC, (1998a). Effects of melatonin implants in pony mares. 2. Long-term effects. Theriogenology. 49(6), 1125-1142.

29. Peltier MR, Robinson G, Sharp DC, (1998b). Effects of melatonin implants in pony mares. 1. Acute effects. Theriogenology. 49(6), 1113-1123.

30. Provinciali M, Di Stefano G, Bulian D, Tibaldi A, and Fabris N, (1996). Effect of melatonin and pineal grafting on thymocyte apoptosis in aging mice. Mech Ageing Dev. 90(1), 1-19.

31. Reiter RJ, (1991a). Neuroendocrine effects of light. Int J Biometeorol. 35, 169-175.

32. Reiter RJ, (1991b). Pineal melatonin: cell biology of its synthesis and of its physiological interactions. Endocrine Reviews. 12(2), 151-80.

33. Reiter RJ, Tan DX, Osuna C, Gitto E, (2000). Actions of melatonin in the reduction of oxidative stress. J Biomed Sci. 7, 444-458.

34. Rios ER, Venâncio ET, Rocha NF, Woods DJ, Vasconcelos S, Macedo D, Sousa FC, Fonteles MM, (2010). Melatonin: Pharmacological Aspects and Clinical Trends. Int J Neurosci. 120(9), 583-590.

35. Satué K, Gardón JC, (2013). Review of the Estrous Cycle and the Neuroendocrine Mechanisms in the Mare. J Steroids Horm Sci. 4(2), 115.

36. Sewerynek E. Melatonin and the cardiovascular system. Neuro Endocrinol Lett. 23 Suppl 1, 79-83.

37. Simonneaux V, Ribelayga C, (2003). Generation of the Melatonin Endocrine Message in Mammals: A Review of the Complex Regulation of Melatonin Synthesis by Norepinephrine, Peptides, and Other Pineal Transmitters. Pharmacol Rev. 55(2), 325-395.

38. Slaugenhaupt SA, Roca AL, Liebert CB, Altherr MR, Gusella JF, Reppert SM, (1995). Mapping of the gene for the Mella-melatonin receptor to human chromosome 4 (MTNR1A) and mouse chromosome 8 (Mtnr1a). Genomics. 27(2), 355-357. 
39. Srinivasan V, Spence DW, Pandi-Perumal SR, Trakht I, Cardinali DP, (2008). Jet lag: Therapeutic use of melatonin and possible application of melatonin analogs. Travel Med Infect Dis. 6(1-2), 17-28.

40. Topal T, Korkmaz A, (2009). Melatonin ve kanserle ilişkisi. Genel Tip Derg. 19(3), 137-143.

41. Touitou Y, Le Hoang P, Claustrat B, Attye T, Auzeby A, Brun J, Bogdan A, Touitou C, (1986). Decreased nocturnal plasma melatonin peak in patients with a functional alteration of the retina in relation with uveitis. Neurosci Lett. 70(1), 170-174.

42. Uyar A, Alan M, (2008). Koyunlarda Erken Anöstrüs Döneminde Melatonin Uygulamalarının Ovulasyon ve Gebelik Üzerine Etkisi. YYÜ vet fak derg. 19(1), 47-54.

43. Waterhouse J, Reilly T, Atkinson G, Edwards B, (2007). Jet lag: trends and coping strategies. Lancet. 369, 1117-1129.
44. Williams GL, Thorson JF, Prezotto LD, Velez IC, Cardoso RC, Amstalden M, (2012). Reproductive seasonality in the mare: neuroendocrine basis and pharmacologic control. Domest Anim Endocrinol. 43(2), 103-115.

45. Witt-Enderby PA, Bennett J, Jarzynka MJ, Firestine S, Melan MA, (2003). Melatonin receptors and their regulation: biochemical and structural mechanisms. Life Sci. 72, 2183-2198.

46. Wurtman RJ, Axelrod J, Chu EW, (1963). Melatonin, a pineal substance: Effect on the rat ovary. Science. 141, $277-$ 278.

47. Yazıcı C, Köse K, (2004). Melatonin: karanlığın antioksidan gücü. E.Ü.Journal of Health Sciences. 13(2), 56-65.

48. Yonei Y, Hattori A, Tsutsui K, Okawa M, Ishizuka B, (2010). Effects of Melatonin: Basics Studies and Clinical Applications. Anti-Aging Medicine. 7(7), 85-89. 